\title{
Survivin family proteins as novel molecular determinants of doxorubicin resistance in organotypic human breast tumors
}

\author{
Alice Faversani ${ }^{1}$, Valentina Vaira ${ }^{1}$, Giacomina P Moro ${ }^{2}$, Delfina Tosi ${ }^{3}$, Alessia Lopergolo ${ }^{4}$, David C Schultz ${ }^{5}$, \\ Dayana Rivadeneira ${ }^{6}$, Dario C Altieri ${ }^{6 *+}$ and Silvano Bosari ${ }^{1,7^{*}+}$
}

\begin{abstract}
Introduction: The molecular determinants of breast cancer resistance to first-line anthracycline-containing chemotherapy are unknown.
\end{abstract}

Methods: We examined the response to doxorubicin of organotypic cultures of primary human breast tumors ex vivo with respect to cell proliferation, DNA damage and modulation of apoptosis. Samples were analyzed for genome-wide modulation of cell death pathways, differential activation of p53, and the role of survivin family molecules in drug resistance. Rational drug combination regimens were explored by high-throughput screening, and validated in model breast cancer cell types.

Results: Doxorubicin treatment segregated organotypic human breast tumors into distinct Responder or Non Responder groups, characterized by differential proliferative index, stabilization of p53, and induction of apoptosis. Conversely, tumor histotype, hormone receptor or human epidermal growth factor receptor-2 (HER2) status did not influence chemotherapy sensitivity. Global analysis of cell death pathways identified survivin and its alternatively spliced form, survivin- $\Delta$ Ex3 as uniquely overexpressed in Non Responder breast tumors. Forced expression of survivin- $\Delta$ Ex3 preserved cell viability and prevented doxorubicin-induced apoptosis in breast cancer cell types. High-throughput pharmacologic targeting of survivin family proteins with a small-molecule survivin suppressant currently in the clinic (YM155) selectively potentiated the effect of doxorubicin, but not other chemotherapeutics in breast cancer cell types, and induced tumor cell apoptosis.

Conclusions: Survivin family proteins are novel effectors of doxorubicin resistance in chemotherapy-naive breast cancer. The incorporation of survivin antagonist(s) in anthracycline-containing regimens may have improved clinical activity in these patients.

\section{Introduction}

Despite considerable progress in the molecular characterization [1], and treatment [2] of breast cancer, drugresistant disease remains a common occurrence, often heralding high morbidity and mortality due to metastatic progression. The molecular underpinnings of treatmentresistant breast cancer, which includes insensitivity to antiestrogen regimens [3], and refractoriness to epidermal

\footnotetext{
* Correspondence: daltieri@wistar.org; silvano.bosari@unimi.it

${ }^{\dagger}$ Equal contributors

${ }^{6}$ Molecular and Cellular Oncogenesis Program, The Wistar Institute, 3601 Spruce Street, Philadelphia, PA 19104, USA

'Division of Pathology, Fondazione IRCCS Ca' Granda Ospedale Maggiore Policlinico, via F. Sforza 35, Milan 20122, Italy

Full list of author information is available at the end of the article
}

growth factor receptor-2 (HER2) inhibitors [4], have been intensely investigated, and linked to aberrant receptor tyrosine kinase signaling [5], enhanced drug efflux mechanisms [6], and defective immune recognition [7]. Although several strategies have been examined to restore treatment sensitivity in these settings [8,9], resistance to the most common, first-line anthracycline-containing chemotherapy [10] continues to represent a significant challenge [11], with limited, if any, 'actionable' molecular targets to restore drug sensitivity.

In this context, resistance to apoptosis, or programmed cell death, is a common occurrence of treatment-resistant malignancies [12], involving deregulated expression of cell death modulators of the $\mathrm{Bcl}-2$ [13], or inhibitor of 
apoptosis (IAP) [14] gene family, including survivin [15]. In chemotherapy-resistant breast cancer, these pathways further compound other aberrant mechanisms of cell survival, including loss of the PTEN tumor suppressor gene [16], reactivation of phosphatidylinositol 3-kinase (PI3K)/ mammalian target of rapamycin (mTOR) signaling [17], expansion of cancer-initiating, progenitor-like cells [18], and increased production of vascular endothelial cell growth factor (VEGF) [19]. Although many of these pathways contain 'actionable' molecular targets, a key challenge in dissecting their role in drug resistance is the paucity of reliable disease model(s) that recapitulate the complexity of the human disease, while preserving the integrity of the tumor microenvironment, as a recognized disease driver in breast cancer [20]. To overcome this barrier, short-term ex vivo cultures of organotypic primary human tumors may provide a flexible translational platform, suitable to evaluate the impact of deregulated signaling pathways [21], and molecular therapies [22], under conditions that preserve tumor architecture [20].

In this study, we used fresh organotypic tissue cultures from treatment-naïve human breast tumors to explore the molecular requirements of anthracycline resistance [10]. We identified a discrete subgroup of doxorubicininsensitive, that is Non Responder tumors, characterized by high proliferative index, impaired p53 responses and resistance to apoptosis. In turn, molecular analyses demonstrated that aberrant overexpression of survivin family proteins [15] is required to maintain the Non Responder phenotype, opening fresh opportunities for rational combination regimens to restore anthracycline sensitivity in these patients.

\section{Methods}

\section{Patient cohort}

Primary human breast tumors were obtained from 33 patients who underwent surgery for therapeutic purposes at San Paolo Hospital (Milan, Italy). The clinicopathologic and molecular characteristics of the patients analyzed in this study are presented in Table 1 . Patients who received neoadjuvant chemotherapy and/or radiotherapy were excluded from the study. Informed consent was obtained from all patients and the study was approved by the Institutional Review Board of the San Paolo Hospital.

\section{Tissue slice preparation}

Tissue processing was performed within 20 minutes after surgical resection. Tissue slices (400 $\mu \mathrm{m}$ thick) were obtained through serial cutting of the individual samples using a Vibratome VT1200 (Leica Microsystems, Milan, Italy), as described previously [22]. For all specimens a tissue slice was collected at baseline time (T0) and at $24 \mathrm{~h}$ intervals for up to $72 \mathrm{~h}$. At each time point, the individual tissues cultures were harvested, formalin-fixed and paraffin-embedded (FFPE) for morphological and immunohistochemical analysis. For 29 samples, tissue was available for the preparation of a second T0 slice that was snap-frozen and utilized for molecular studies. A pathologist (SB) examined the tissue cultures to verify the presence of tumor cells.

\section{Organotypic tissue cultures and treatment}

Tissue slices were cultured as described [22]. For treatment, doxorubicin (10 $\mu \mathrm{M}$, Sigma-Aldrich, St. Louis, MO, USA) or vehicle (1 $\mu$ l phosphate-buffered saline (PBS), Gibco Invitrogen, Life Technologies, Carlsbad, CA, USA) was added to the culture medium, and replenished at the same concentration every $24 \mathrm{~h}$.

\section{Immunohistochemical analysis}

All samples were analyzed for morphologic integrity and presence of breast cancer cells by hematoxylin and eosin (H\&E) staining. Immunohistochemical scores in tissue cultures and T0 samples were determined in the epithelial tumor cells compartments. Immunostaining was performed for Ki-67 (MIB1, 1:100, Dako, Milan, Italy), estrogen receptor (ER, 1D5, 1:200, Dako), and progesterone receptor (PR, PGR-636, 1:100, Dako) on all samples. Tumor cells immunoreactivity for p53 (Ab5-DO-7, 1:1000, LabVision/NeoMarkers, Fremont, CA, USA), p21 Waf1 (CP-74, 1:1000, Sigma-Aldrich) and MDM2 (Ab1 IF2, 1:100, Oncogene Science, Wilex Inc., Cambridge, MA, USA) could be assessed on 31 FFPE samples. Analysis of cleaved caspase-3 (Asp175, 5A1E, 1:500, Cell Signaling Technology, Danvers, MA, USA) was carried out on 30 samples. Binding of the individual primary antibody was detected with a secondary antibody of appropriate specificity, and visualized by 4',6-diamidino-2-phenylindole (DAB) followed by counterstaining with hematoxylin. Negative controls were prepared in the absence of primary antibody and included in each reaction. Three investigators (AF, VV and SB) independently examined and scored all slides. When discrepancies occurred, the cases were reviewed jointly until a consensus was reached. For quantification of proliferative activity, a Ki-67 score was determined at diagnosis as the percentage of positive tumor cells [23]. The data were correlated to the individual responses to doxorubicin in the organotypic cultures. A Ki-67 score in organotypic cultures of breast tumors was calculated as the percentage of positive cells divided by the entire tumor cell population present in the sample. A two-score system for percentage of positive cells and intensity of staining was used to quantify the reactivity for $\mathrm{p} 53, \mathrm{MDM} 2, \mathrm{p} 21^{\text {waf } 1}$ and cleaved caspase-3. The intensity of staining was expressed in a scale of 0 (absent staining) to 3 (strong staining). A $\mathrm{Ki}-67 /$ cleaved caspase-3 ratio was expressed as growth index (GI) [24]. Data for each time point were normalized to the samples at baseline (T0). Representative images 
Table 1 Clinicopathological and molecular characteristics of breast cancers analyzed $(n=33)^{a}$

\begin{tabular}{|c|c|c|c|c|c|c|c|c|c|c|}
\hline Case & Histotype $^{\text {b }}$ & $\mathrm{T}$ & $\mathbf{N}$ & $\mathrm{G}^{\mathrm{C}}$ & ER & PR & HER2 status ${ }^{d}$ & $\mathrm{Ki}-67^{\mathrm{e}}$ & p53 & Doxo class $^{f}$ \\
\hline BR1 & IDC & pT1c & N1a & G2 & $70 \%$ & $70 \%$ & Neg & $10 \%$ & Wt & Responder \\
\hline BR2 & IDC & pT2 & $\mathrm{pNx}$ & G2 & $90 \%$ & $70 \%$ & Neg & $15 \%$ & R280G & Responder \\
\hline BR3 & IDC & pT3 & N1a & $\mathrm{G} 2$ & $80 \%$ & Neg & Neg & $20 \%$ & Wt & Non Responder \\
\hline BR4 & IDC & pT1c & No & $\mathrm{G} 2$ & $80 \%$ & $10 \%$ & Pos & $10 \%$ & Wt & Non Responder \\
\hline BR5 & IDC & pT2 & N3a & G3 & $80 \%$ & $90 \%$ & Neg & $20 \%$ & $W t$ & Non Responder \\
\hline BR6 & $P C$ & pT2 & $\mathrm{N} 2 \mathrm{a}$ & G3 & $90 \%$ & $5 \%$ & Neg & $10 \%$ & Wt & Responder \\
\hline BR7 & DLC & pT3 & N1 & G3 & $90 \%$ & $5 \%$ & Neg & $30 \%$ & Wt & Responder \\
\hline BR8 & IDC & pT1c & N1a & G3 & $80 \%$ & $70 \%$ & Neg & $25 \%$ & Wt & Responder \\
\hline BR9 & IDC & pT1c & No & G2 & $90 \%$ & $70 \%$ & Neg & $20 \%$ & Wt & Responder \\
\hline BR10 & IDC & pT2 & $\mathrm{Nx}$ & $\mathrm{G} 2$ & $90 \%$ & $95 \%$ & Neg & $15 \%$ & Wt & Responder \\
\hline BR11 & $P C$ & pT2 & No & G1 & $95 \%$ & $95 \%$ & Neg & $10 \%$ & Wt & Responder \\
\hline BR12 & IDC & pT1c & No & G3 & $95 \%$ & $60 \%$ & Neg & $40 \%$ & Wt & Non Responder \\
\hline BR13 & IDC & pT1c & No & $\mathrm{G} 2$ & $90 \%$ & $85 \%$ & Neg & $15 \%$ & Wt & Non Responder \\
\hline BR14 & ILC & pT3 & N3a & G3 & $25 \%$ & $40 \%$ & Pos & $20 \%$ & Wt & Non Responder \\
\hline BR15 & IDC & pT2 & No & G3 & $95 \%$ & $20 \%$ & Neg & $10 \%$ & Wt & Responder \\
\hline BR16 & IDC & pT1c & No & $\mathrm{G} 2$ & $95 \%$ & Neg & Neg & $5 \%$ & Wt & Non Responder \\
\hline BR17 & IDC & pT1c & NO & G2 & $95 \%$ & $95 \%$ & Neg & $20 \%$ & $W t$ & Non Responder \\
\hline BR18 & IDC & pT3 & N3 & G3 & Neg & Neg & Neg & $45 \%$ & Wt & Responder \\
\hline BR19 & IDC & pT2 & $\mathrm{N} 2$ & G3 & $90 \%$ & $60 \%$ & Pos & $90 \%$ & Wt & Non Responder \\
\hline BR20 & IDC & pT2 & N3a & G3 & $90 \%$ & $2 \%$ & Pos & $10 \%$ & Wt & Responder \\
\hline BR21 & IDC & pT2 & $\mathrm{Nx}$ & G3 & $90 \%$ & $80 \%$ & Neg & $30 \%$ & Wt & Non Responder \\
\hline BR22 & IDC & pT1c & NO & G1 & $90 \%$ & $90 \%$ & Neg & $5 \%$ & Wt & Responder \\
\hline BR23 & IDC & pT1c & $\mathrm{Nx}$ & G2 & $90 \%$ & $40 \%$ & Neg & $20 \%$ & Wt & Responder \\
\hline BR24 & IDC & pT1c & $\mathrm{Nx}$ & $\mathrm{G} 2$ & $95 \%$ & $95 \%$ & Neg & $5 \%$ & Wt & Responder \\
\hline BR25 & IDC & pT2 & $\mathrm{N} 2 \mathrm{a}$ & G1 & $90 \%$ & $75 \%$ & Neg & $5 \%$ & $\mathrm{~K} 132 \mathrm{~N}$ & Responder \\
\hline BR26 & IDC & pT2 & N1a & $\mathrm{G} 2$ & $90 \%$ & $70 \%$ & Neg & $10 \%$ & Wt & Non Responder \\
\hline BR27 & IDC & pT1c & No & G3 & $90 \%$ & $90 \%$ & Neg & $20 \%$ & Wt & Non Responder \\
\hline BR28 & IDC & pT2 & N1a & G3 & $90 \%$ & $10 \%$ & Neg & $30 \%$ & Wt & Responder \\
\hline BR29 & IDC & pT1c & No & G3 & $90 \%$ & Neg & Neg & $25 \%$ & Wt & Responder \\
\hline BR30 & IDC & pT1c & N1a & G1 & $95 \%$ & $95 \%$ & Neg & $5 \%$ & Wt & Responder \\
\hline BR31 & IDC & pT1c & NO & G3 & Neg & Neg & Neg & $40 \%$ & Wt & Non Responder \\
\hline BR32 & IDC & pT2 & N1a & G3 & $95 \%$ & $70 \%$ & Neg & $25 \%$ & R248W & Non Responder \\
\hline BR33 & IDC & pT3 & N3a & $\mathrm{G} 2$ & $90 \%$ & $80 \%$ & Neg & $10 \%$ & Wt & Responder \\
\hline
\end{tabular}

${ }^{a}$ Tumor stage according to TNM staging systems, grade, hormone or HER2 receptor status, tumor proliferation (percentage of Ki-67-positive cells), and p53 gene mutations are indicated along with our biological class related to the ex vivo doxorubicin treatment. All patients were M0, that is, no distant metastases were present at diagnosis. ' ${ }^{\mathrm{I}} \mathrm{DC}$, invasive ductal carcinoma; PC, papillary carcinoma; DLC, ductal and lobular carcinoma; ILC, invasive lobular carcinoma. ${ }^{\mathrm{C}} \mathrm{G}$, tumor grade. ${ }^{\mathrm{d} H E R 2}$ status was determined according to American Society of Clinical Oncology guidelines (2007). ${ }^{\mathrm{e}} \mathrm{Ki}-67$ index as determined at diagnosis (approximate to the nearest 5\%). fDoxorubicin class was assigned to breast cancers depending on the decrease of proliferating cells upon ex vivo doxorubicin treatment of at least $50 \%$ (Responders) or the maintenance of Ki-67-positive cells similar to control treated cultures (Non Responders).

were obtained using an LMD108 system (Leica Microsystems) and contrast/brightness was adjusted using Photoshop (Adobe Systems Inc., San Jose, CA, USA).

\section{p53 mutational analysis}

DNA was purified from frozen or FFPE samples at T0 and amplified with specific primers for p53 exons 5 to 9
(Table S1 in Additional file 1). Both amplicon strands were sequenced using the BigDye Terminators chemistry (Applied Biosystems, Life Technologies, Carlsbad, CA, USA), and purified using DyeEx 2.0 Spin Kit (Qiagen, Manassas, VA, USA). DNA sequences were performed using a 3130 Genetic Analyzer (Applied Biosystems, Life Technologies). 


\section{RNA purification and reverse transcription}

Total RNA was extracted from frozen tissues using RNeasy Mini Kit (Qiagen) according to the supplier's protocol. One $\mu \mathrm{g}$ of total RNA was reverse-transcribed using High-Capacity cDNA Reverse Transcription Kit (Applied Biosystems, Life Technologies).

\section{Apoptotic gene profiling}

Gene expression analysis of apoptotic-related genes was analyzed in five Responder and five Non Responder cases of organotypic breast tumors using RNA purified from T0 samples before culture by custom Microfluidic Cards technology (Applied Biosystems, Life Technologies). This platform allows for simultaneous expression analysis of 92 apoptosis-related genes (Table S2 in Additional file 1) and three reference genes (ACTB, TBP and HMBS) for target gene relative quantification. Eight hundred ng of cDNA for each sample was loaded in duplicate per card, analyzed using an ABI Prism 7900HT sequence detection system, and targets raw data (Ct values) were converted into relative quantities using GeNorm software [25]. Relative quantity RQ values were then mediannormalized and $\log 2$-transformed for statistical analysis. All reagents, instruments and software were by Applied Biosystems, Life Technologies.

\section{Real time RT-PCR (qPCR)}

Gene expression levels of tumor necrosis factor-alpha (TNF $\alpha$ ), baculoviral IAP repeat- containing 3 (BIRC3), survivin (BIRC5) isoform 1, survivin-2B (isoform 3), or survivin- $\triangle \mathrm{Ex} 3$ (isoform 2) were analyzed in duplicate using gene-specific primers and probes (Table S3 in Additional file 1 ) and the ABI Prism $7900 \mathrm{HT}$ sequence detection system. $\beta-2$ microglobulin $(\beta 2 \mathrm{M})$ was used as reference gene for target genes relative quantification using the $2^{-\Delta \mathrm{Ct}}$ formula.

\section{In vitro experiments}

Human breast cancer MCF-7, MDA-MB231 and HS578T cells were obtained from the American Type Culture Collection (ATCC, Manassas, VA, USA) and maintained in culture in Dulbecco's modified Eagle's medium (DMEM) containing $10 \%$ fetal bovine serum (FBS) supplemented with $100 \mathrm{U} / \mathrm{ml}$ penicillin/streptomycin and $2 \mathrm{mM} \mathrm{L}$-glutamine at $37^{\circ} \mathrm{C}$ and $5 \% \mathrm{CO}_{2}$, as recommended by the supplier. MCF-7 cells $\left(2 \times 10^{6} /\right.$ well in a six-well plate) were transfected with $2 \mu \mathrm{g}$ of vectors containing survivin- $\Delta \mathrm{Ex} 3$ cDNA or control plasmid [26] in the presence of lipofectamine 2000 (Invitrogen, Life Technologies, Carlsbad, CA, USA) for $24 \mathrm{~h}$. Transfected cells were treated with $1 \mu \mathrm{M}$ doxorubicin or vehicle (PBS) for $24 \mathrm{~h}$, released for additional $24 \mathrm{~h}$ and analyzed for functional experiments.

\section{Immunofluorescence}

Snap-frozen tissue sections derived from seven organotypic breast tumors or MCF-7 cells were fixed in 4\% paraformaldehyde (PFA) (Sigma-Aldrich), and incubated with a primary antibody to phospho-histone H2AX (pSer ${ }^{139}$ ) $\left(\gamma \mathrm{H} 2 \mathrm{AX}, 1: 700\right.$, Sigma-Aldrich) for $16 \mathrm{~h}$ at $22^{\circ} \mathrm{C}$. Antirabbit 647 or 548 Alexa Fluor-conjugated was used as a secondary antibody (Molecular Probes, Invitrogen), and nuclei were stained with 4',6-diamidino-2-phenylindole (DAPI) (Abbott Laboratories, Abbott Park, IL, USA). Slides were scored by fluorescence microscopy using an AxioImager Z1 microscope (Carl Zeiss, Göttingen, Germany) and photographed images were arranged with Photoshop. For each sample, 100 cells were analyzed and the H2AX phosphorylation index was calculated as a percentage of $\gamma \mathrm{H} 2 \mathrm{AX}$-positive cells [26].

\section{Cell viability and TUNEL assays}

Cell viability was assessed in MCF-7 cells in the presence of $5 \mathrm{mg} / \mathrm{ml}$ of 3-(4,5-dimethylthiazol-2-yl)-2,5 diphenyltetrazolium bromide assay (MTT, Sigma-Aldrich) for $4 \mathrm{~h}$ at $37^{\circ} \mathrm{C}$, and determination of absorbance at $570 \mathrm{~nm}$. Apoptotic cells were quantified by terminal deoxynucleotidyl transferase dUTP nick-end labeling (TUNEL) assay using an ApopTag In Situ Apoptosis Detection Kit (Millipore, Billerica, MA, USA) following the manufacturer's protocol.

For combination experiments, MCF-7 or HS578T cells were incubated with $5 \mathrm{nM}$ of the survivin smallmolecule suppressant YM155 (Selleckchem, Houston, $\mathrm{TX}$, USA) prepared as stock solutions $(10 \mu \mathrm{M})$ in dimethyl sulfoxide (DMSO) in the presence or absence of doxorubicin (1 to $4 \mu \mathrm{M}$, Selleckchem) or vehicle (DMSO). MDA-MB231 cells were incubated with 10 nM YM155. After $24 \mathrm{~h}$ incubation, cells under the various conditions tested were analyzed for cell viability by Trypan blue exclusion and light microscopy. Alternatively, treated MCF-7 cells were washed in PBS, pH 7.2, fixed in cold 70\% ethanol overnight at $4^{\circ} \mathrm{C}$, stained with propidium iodide $(0.2 \mathrm{~g} / \mathrm{ml})$, and analyzed for DNA content by flow cytometry on a FACSCalibur instrument (Beckman Coulter, Indianapolis, IN, USA). Cell death was quantified in three independent experiments by detection of a population with hypodiploid (sub-G1) DNA content using FlowJo Software (Tree Star, Inc., Ashland, OR, USA). In other experiments, drug-treated MCF-7 cells were analyzed by Western blotting with primary antibodies to cleaved caspase-3 (Asp175) (Cell Signaling), or poly-ADP ribose polymerase (PARP) (46D11) (Cell Signaling). An antibody to $\beta$-actin (SigmaAldrich) was used as control.

\section{Synergy studies}

MCF-7 cells $\left(1.7 \times 10^{4} / \mathrm{cm}^{2}\right)$ were treated simultaneously with YM155 (0.0004 to $0.1 \mu \mathrm{mol} / \mathrm{L})$ and either doxorubicin, taxol, camptothecin, or etoposide (dose range for each 
agent 0.004 to $1 \mu \mathrm{mol} / \mathrm{L}$ ) in a $7 \times 7$ matrix of concentrations for $48 \mathrm{~h}$. Cell viability under the various conditions tested was determined by the addition of resazurin to a final concentration of $50 \mu \mathrm{M}$ and incubation for $5 \mathrm{~h}$. Fluorescence intensity (excitation, $560 \mathrm{~nm}$; emission, $590 \mathrm{~nm}$ ) was measured on an Envision Xcite Multilabel Reader (Perkin-Elmer, Waltham, MA, USA), and the fractional growth inhibition was determined by normalizing assay wells $(n=2)$ to the aggregated average responses of positive control (10 $\mu \mathrm{M}$ doxorubicin) and negative control $(0.2 \%$ DMSO) treatments $(\mathrm{n}=12)$. Synergy between YM155 and chemotherapeutic agents was determined by Bliss independence analyses [27]. The Bliss expectation (E) for a combined response was calculated by the equation: $\mathrm{E}=(\mathrm{A}+\mathrm{B})-(\mathrm{A} \times \mathrm{B})$ where $\mathrm{A}$ and $\mathrm{B}$ are the fractional growth inhibitions of drug $\mathrm{A}$ and $\mathrm{B}$ at a given dose. The difference between the Bliss expectation and the observed growth inhibition of the combination of drugs A and B at the same dose is the 'Excess over Bliss'. Excess over Bliss scores $=0$ indicates that the combination treatment is additive (as expected for independent pathway effects); Excess over Bliss scores $>0$ indicates activity greater than additive (synergy); and Excess over Bliss scores $<0$ indicates the combination is less than additive (antagonism). Each experiment was independently repeated twice with comparable results.

\section{Statistical analysis}

Data were analyzed using Prism 4.0 (GraphPad Inc, La Jolla, CA, USA). Differences among sample groups were analyzed using the unpaired Student's $t$ test. The association between Ki-67 levels and clinicopathological or molecular parameters in the various patients was evaluated by Fisher's exact test. The expression profiling of apoptotic genes in organotypic breast tumors was analyzed using the web-based BRB-ArrayTools software [28] and Ingenuity Pathway system (Ingenuity Systems Inc., Redwood City, CA, USA). Statistical significance was assumed for a probability value $(P)$ less than 0.05 .

\section{Results}

\section{Organotypic breast tumor responses to DNA-damaging} agents

We began this study by examining the response of 33 treatment-naïve ex vivo human breast tumors [22] to anthracycline-containing therapy. Treatment of organotypic breast tumors with doxorubicin $(10 \mu \mathrm{M})$ decreased cell proliferation at 24-h time intervals, throughout a 72-h culture (Figure 1A). In contrast, administration of vehicle had no effect on tumor cell proliferation in these settings (Figure 1A). Doxorubicin treatment did not alter the hormone receptor status of ex vivo breast tumors, including estrogen and progesterone receptors (Figure S1A and $\mathrm{B}$ in Additional file 1). Consistent with a predicted induction of DNA damage, doxorubicin-treated organotypic cultures exhibited high levels of phosphorylated histone H2AX $(\gamma \mathrm{H} 2 \mathrm{AX})$, a cellular marker of double-strand DNA breaks (DSB) (Figure 1B), compared to vehicletreated cultures or tumors harvested at baseline conditions (Figure 1C). Under these conditions, doxorubicin treatment identified two discrete subgroups of ex vivo breast tumors, characterized by radically different proliferative responses. In 19 out of 33 samples (57\%), treatment with doxorubicin induced a decrease in proliferating cells over the last time interval (Figure 1D) equal to or greater than 50\% (Ki-67 immunoreactivity range, 0 to 50\%), compared to control cultures (Figure 1E). These breast tumors were designated as Responders in our study. Conversely, the remaining 14 breast tumors (42\%) exhibited no significant decrease in proliferative index throughout exposure to doxorubicin (Figure 1F), quantitatively indistinguishable to that of vehicle-treated cultures (Ki-67 immunoreactivity range 70 to $180 \%$; Figure $1 G$ ). These doxorubicin-resistant breast tumors were designated as Non Responders in the study. Consistent with this working classification, organotypic breast tumors in the Responder group exhibited a lower proliferative index at diagnosis with $<15 \%$ Ki-67positive cells, whereas tumors in the Non Responder group had higher proliferative index, by Ki-67 staining (mean levels: $16 \%$ versus $26 \%$, respectively, $P=0.04$; Figure $1 \mathrm{H})$. No other significant association was observed between the different levels of Ki-67 immunoreactivity in Responder and Non Responder breast tumors and histologic type $(P=0.1)$, tumor size $(P=0.7)$, lymph node status $(P=0.2)$, hormone receptor expression (ER, $P=0.8$; PR, $P=0.3)$, or HER2 status $(P=0.2)$. As expected, Ki-67 immunoreactivity displayed a trend to associate with tumor grade $(P=0.06)$.

\section{Differential regulation of apoptosis in organotypic breast tumors}

In addition to decreased cell proliferation, treatment of organotypic breast tumors with doxorubicin resulted in increased expression of cleaved, that is active caspase-3, a marker of terminal activation of apoptosis (Figure 2A). When stratified according to the Responder versus Non Responder classification, doxorubicin induced caspase-3 cleavage almost exclusively in the Responder population of breast tumors (Figure $2 \mathrm{~B}$ and $\mathrm{C}$ ). In contrast, Non Responder samples had virtually no increase in active caspase-3 generation after doxorubicin treatment throughout a 72-h culture (Figure $2 \mathrm{~B}$ and C). Similarly, Responder breast tumors exhibited progressive suppression of a GI, calculated as the ratio between Ki-67 immunoreactivity and cleaved caspase- 3 in response to doxorubicin treatment (24) (Figure 2D). In contrast, Non Responder tumors continued to exhibit high GI throughout a 72-h doxorubicin treatment (Figure 2D). Despite the extensive 

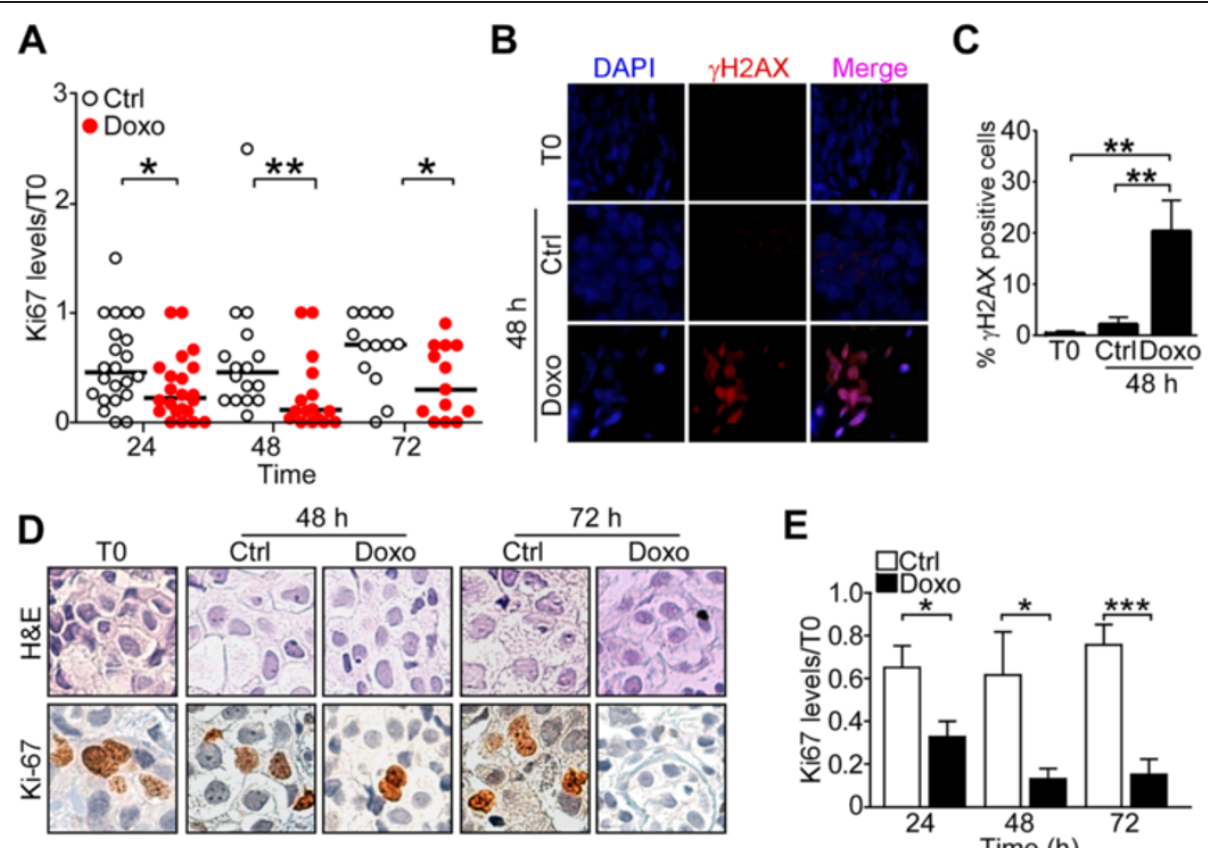

E
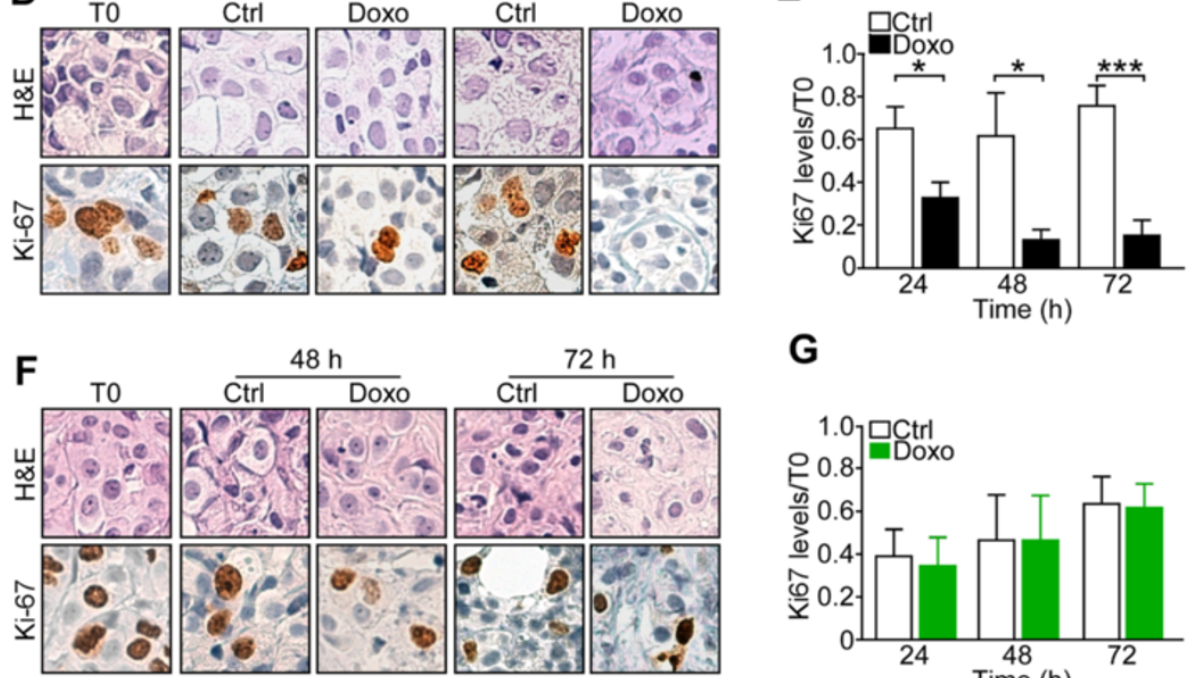

G
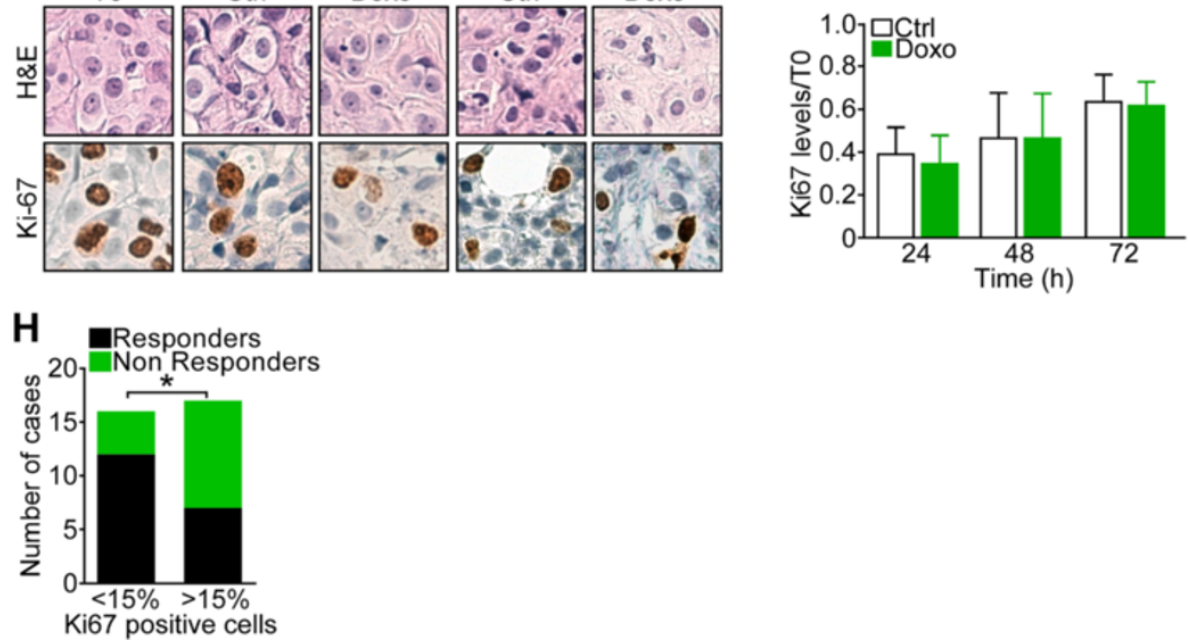

Figure 1 Response of organotypic breast tumors to doxorubicin. (A) Ex vivo cultures of primary human breast tumors $(n=33)$ were incubated with $10 \mu \mathrm{M}$ doxorubicin (Doxo) for the indicated time intervals, and analyzed for Ki-67 expression compared to baseline levels (T0), by immunohistochemistry. ${ }^{*} P=0.03 ;{ }^{* *} P=0.009$ (unpaired $t$ test). Each circle corresponds to an individual tumor. (B, C) Ex vivo tumor samples were analyzed for phosphorylation of histone $\mathrm{H} 2 \mathrm{AX}(\mathrm{\gamma H} 2 \mathrm{AX}$ ) by immunofluorescence, with quantification of $\mathrm{\gamma H} 2 \mathrm{AX}$-reactive cells after $48 \mathrm{~h}$ (C). ${ }^{* *} P=0.002$ (unpaired $t$ test). (D) Responder breast tumors $(n=19)$ were treated with Doxo or vehicle $(C t r l)$ and analyzed for changes in cell proliferation by Ki-67 expression relative to T0 baseline at the indicated time intervals. Original magnification $\times 200$. (E) Quantification of Ki-67 expression in Responder breast tumors treated with Doxo or Ctrl for the indicated time intervals. ${ }^{*} P=0.02 ;{ }^{*} P=0.0003$ (unpaired $t$ test). (F) Non Responder breast tumors $(n=14)$ were treated with Ctrl or Doxo, and analyzed for Ki-67 expression relative to T0 as in (D). Original magnification x200. (G) Quantification of Ki-67 expression in Non Responder breast tumors treated with Doxo or Ctrl for the indicated time intervals. (H) Responders and Non Responders breast tumors were analyzed for baseline Ki-67 immunoreactivity (\% of positive nuclei). ${ }^{*} P=0.04$ (Fisher's exact test). For all experiments, bars represent mean \pm SEM.

differences in proliferative, apoptotic and growth markers (Figures 1, 2), Responder and Non Responder breast tumors showed comparable reactivity for $\gamma \mathrm{H} 2 \mathrm{AX}$ induction in response to doxorubicin treatment (Figure 2E).
As an upstream regulator of apoptosis and cell cycle arrest in response to DNA damage, we next investigated a potential differential activation of $\mathrm{p} 53$ in organotypic breast tumors. Doxorubicin treatment resulted in increased 

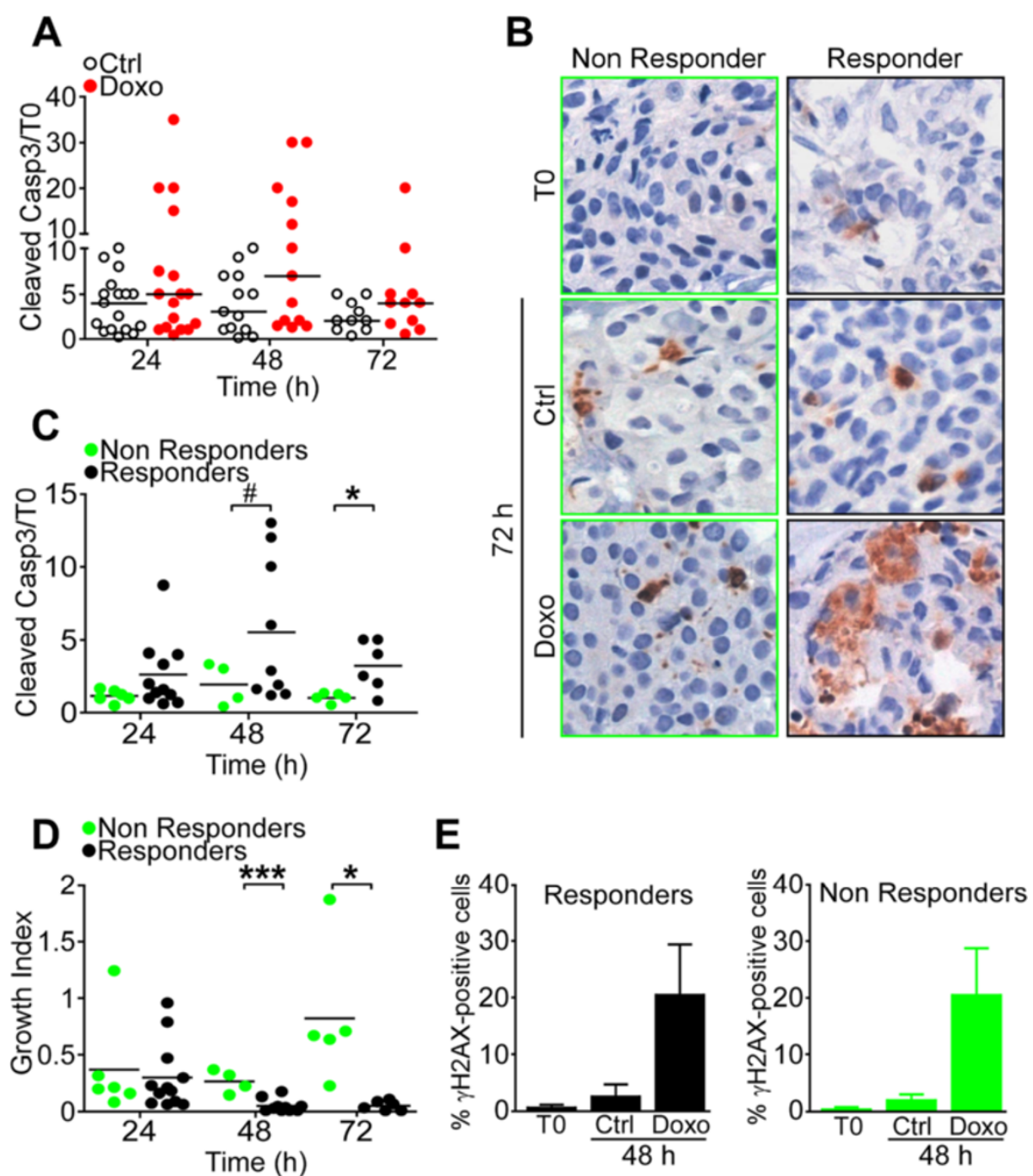

Figure 2 Differential induction of apoptosis in doxorubicin-treated organotypic breast tumors. (A) Breast tumors $(n=33)$ were incubated with $10 \mu \mathrm{M}$ doxorubicin (Doxo) for the indicated time intervals and analyzed for cleaved caspase-3 (Casp3), by immunohistochemistry. (B) Responder $(n=19)$ versus Non Responder $(n=14)$ breast tumors were analyzed for Casp3 expression after $72 \mathrm{~h}$ treatment with vehicle (Ctrl) or Doxo by immunohistochemistry. Original magnification x 400. (C) Quantification of Casp3 immunoreactivity in Non Responder versus Responder breast tumors at the indicated time intervals after Doxo treatment. ${ }^{\#} P=0.04 ;{ }^{*} P=0.02$. (D) Quantification of growth index (GI) in Responder versus Non Responder breast tumors at the indicated time intervals after Doxo treatment. ${ }^{*} P=0.02 ;{ }^{* * *} P=0.0005$ (unpaired $t$ test). Each circle corresponds to an individual tumor. (E) $\mathrm{yH} 2 \mathrm{AX}$-reactive cells were quantified after $48 \mathrm{~h}$ treatment with Doxo in Responder or Non Responder breast tumors by fluorescence microscopy. For all experiments, bars represent mean \pm SEM.

expression of p53 (Figure S2A in Additional file 1), and upregulation of its transcriptional target, p $21^{\text {waf1 }}$ (Figure S2B in Additional file 1). In contrast, protein levels of the p53 regulator, MDM2 were not significantly affected (Figure S2C in Additional file 1). When analyzed in the functional tumor subgroups, doxorubicin-induced immunoreactivity for p53 (Figure 3A and B) and p21 waf1 (Figure $3 \mathrm{~A}$ and $\mathrm{C}$ ) almost exclusively segregated with Responder tumors throughout a 24- to 48-h treatment. In contrast, Non Responder tumors did not exhibit p53 stabilization (Figure 3A), or upregulation of p21 waf1 (Figure $3 \mathrm{~A}$ and $\mathrm{C}$ ) after exposure to doxorubicin for the same time intervals. Although no changes in MDM2 levels were observed in unfractionated organotypic tumors (Figure S2C in Additional file 1), analysis of tumor subgroups revealed a significant increase in MDM2 protein levels in Responder compared to Non Responder breast tumors (Figure 3A and D). The differences in $\mathrm{p} 53$ pathway induction in Responder versus Non Responder breast tumors was independent of p53 gene mutations, as sequence analysis of p53 exons 5 to 9 revealed comparable mutation frequencies among Responder and Non Responder samples $(10 \%$ and $7 \%$, respectively, $P=$ 0.73; Table 1). 
A

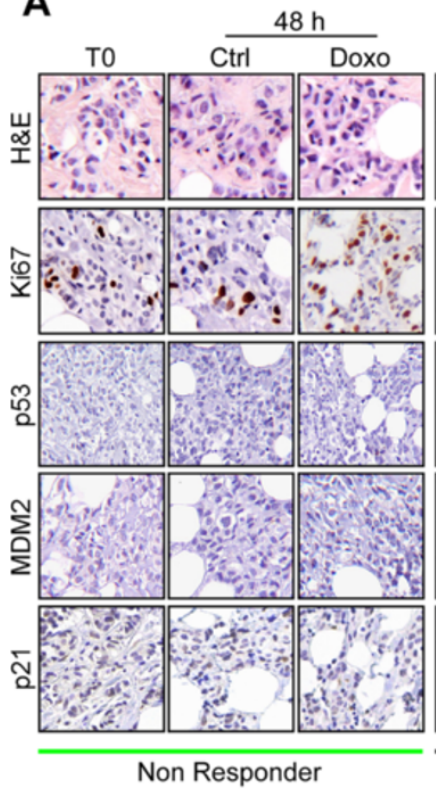

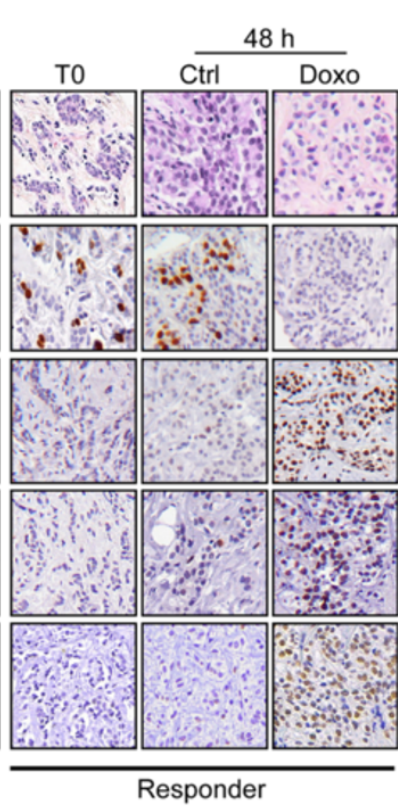
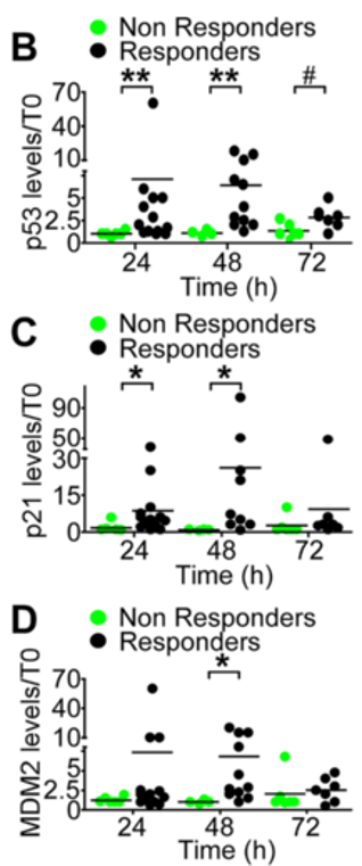

Figure 3 Differential p53 pathway activation in organotypic breast tumors. (A) Immunohistochemical analysis of differential expression of p53, p21 $1^{\text {Waf1 }}$ or MDM2 in control (Ctrl)- or doxorubicin (Doxo)-treated breast tumors after 48 h. Tissue morphology and proliferative index were determined by hematoxylin and eosin (H\&E) and Ki-67 staining of the same cases, respectively. A representative case for Non Responder (left) or Responder (right) breast tumors ex vivo is shown. Original magnification, x200. (B-D) Quantification of p53 (B), p21 Waf1 (C) or MDM2 (D) proteins levels in Ctrl or Doxo-treated Responder versus Non Responder breast tumors at the indicated time intervals. ${ }^{\#} P=0.03{ }^{*} P=0.01 ;{ }^{*} P=0.007$ (unpaired $t$ test).

Role of survivin family proteins in doxorubicin resistance in organotypic breast tumors

To identify a potential molecular basis of doxorubicin resistance in ex vivo breast tumors, we next looked at the expression of 92 apoptotic regulatory genes in organotypic breast tumors at T0 baseline. Array profiling studies revealed a global deregulation of p53 pathway activation in Non Responder versus Responder tumors (Figure S3A in Additional file 1), potentially affecting DNA damage-induced cell death, cell cycle transitions, and tumor metabolic reprogramming (Figure S3B in Additional file 1). Specifically, supervised analysis of array profiling data identified BIRC5 (survivin), BIRC3 (cIAP2) and TNF $\alpha$ as the most deregulated transcripts in Non Responder tumors under these conditions (Figure S3A in Additional file 1). Consistent with these findings, wildtype survivin (Figure S3C in Additional file 1), and its alternatively spliced variant survivin- $\triangle \mathrm{Ex} 3 \quad(P=0.006$, Figure S3D in Additional file 1 ), were validated by quantitative PCR as significantly differentially expressed in Non Responder versus Responder tumors $(n=29)$. In contrast, the survivin splice variant survivin-2B was comparably expressed in the two subgroups of organotypic breast tumors (Figure S3E in Additional file 1). Despite a trend was observed for differential increased expression of TNFa (Figure S4A in Additional file 1), and BIRC3
(Figure S4B in Additional file 1) in Non Responder compared to Responder tumors, these changes did not reach statistical significance. Although survivin functions as a broad apoptosis inhibitor and mitotic regulator in genetically heterogeneous tumors [29], survivin- $\Delta \mathrm{Ex} 3$ has been selectively associated with modulation of the DNA damage response, selectively in tumors [26]. Accordingly, survivin- $\triangle \mathrm{Ex} 3$ was differentially expressed in breast tumors with high proliferative index, as determined by Ki-67 immunoreactivity ( $>15 \% \mathrm{Ki}-67^{+}$cells; Figure $4 \mathrm{~A}$, $P=0.03)$. Mechanistically, overexpression of survivin- $\triangle \mathrm{Ex} 3$ in MCF-7 cells treated with doxorubicin (Figure S5A in Additional file 1$)$ prevented loss of cell viability $(P=0.02$; Figure 4B), and significantly decreased the number of apoptotic cells $(P=0.01$; Figure $4 C)$ after doxorubicin treatment. In control experiments, forced expression of survivin- $\triangle \mathrm{Ex} 3$ did not affect DNA foci formation in MCF-7 cells, as determined by $\gamma \mathrm{H} 2 \mathrm{AX}$-nuclear staining (Figure S5B and C in Additional file 1).

\section{Incorporation of survivin-based molecular therapy in breast cancer treatment}

The results above suggest that survivin family proteins may function as key determinants of doxorubicinresistance in organotypic breast tumors. To further test this possibility, we next used a high-throughput format 

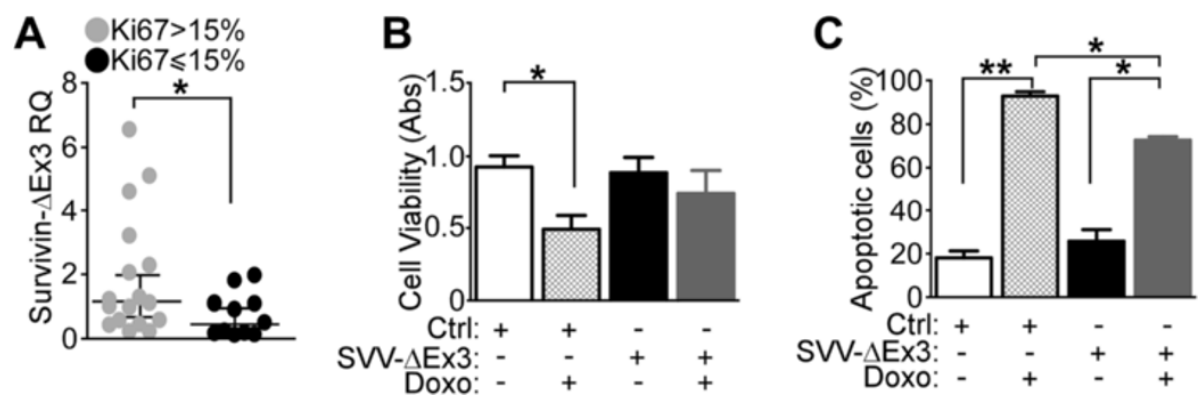

Figure 4 Role of survivin family proteins in doxorubicin resistance in breast cancer. (A) Human breast tumors with low (Ki-67 $\leq 15 \%)$ or high (Ki-67 > 15\%) proliferative index were analyzed for differential expression of survivin- $\triangle \mathrm{Ex} 3$ by $\mathrm{qPCR}$. ${ }^{*} P=0.03$. (B, C) MCF-7 cells were transfected with survivin- $\Delta \mathrm{Ex} 3(\mathrm{SW}-\Delta \mathrm{E} \times 3)$ or control vector (Ctrl), treated with $1 \mu \mathrm{M}$ doxorubicin or vehicle, and analyzed for cell viability (B) or apoptosis (C) after $48 \mathrm{~h}$ by an 3-(4,5-dimethylthiazol-2-yl)-2,5 diphenyltetrazolium bromide (MTT) or terminal deoxynucleotidyl transferase dUTP nick-end labeling (TUNEL) assay, respectively. ${ }^{*} P=0.01 ;{ }^{*} P=0.002$ (unpaired $t$ test).

to examine combination regimens of first-line anthracycline chemotherapy plus the small-molecule survivin suppressant, sepantronium bromide (YM155) currently evaluated in the clinic [30]. The combination of YM155 plus doxorubicin in these settings produced extensive antitumor synergy against breast cancer MCF-7 cells (Figure 5), and robust inhibition of cell proliferation at various concentrations of the two agents tested (Figure 6A). In contrast, the combination of YM155 with taxol, camptothecin (CPT) or etoposide was not synergistic and produced suboptimal antitumor activity against breast cancer cells (Figure 5). Consistent with these findings, the addition of YM155 significantly enhanced doxorubin-mediated killing of a panel of genetically heterogeneous breast cancer cell types, compared to each treatment alone (Figure 6B). When analyzed for mechanisms of antitumor activity, the combination of YM155 plus doxorubicin increased the fraction of tumor cells with

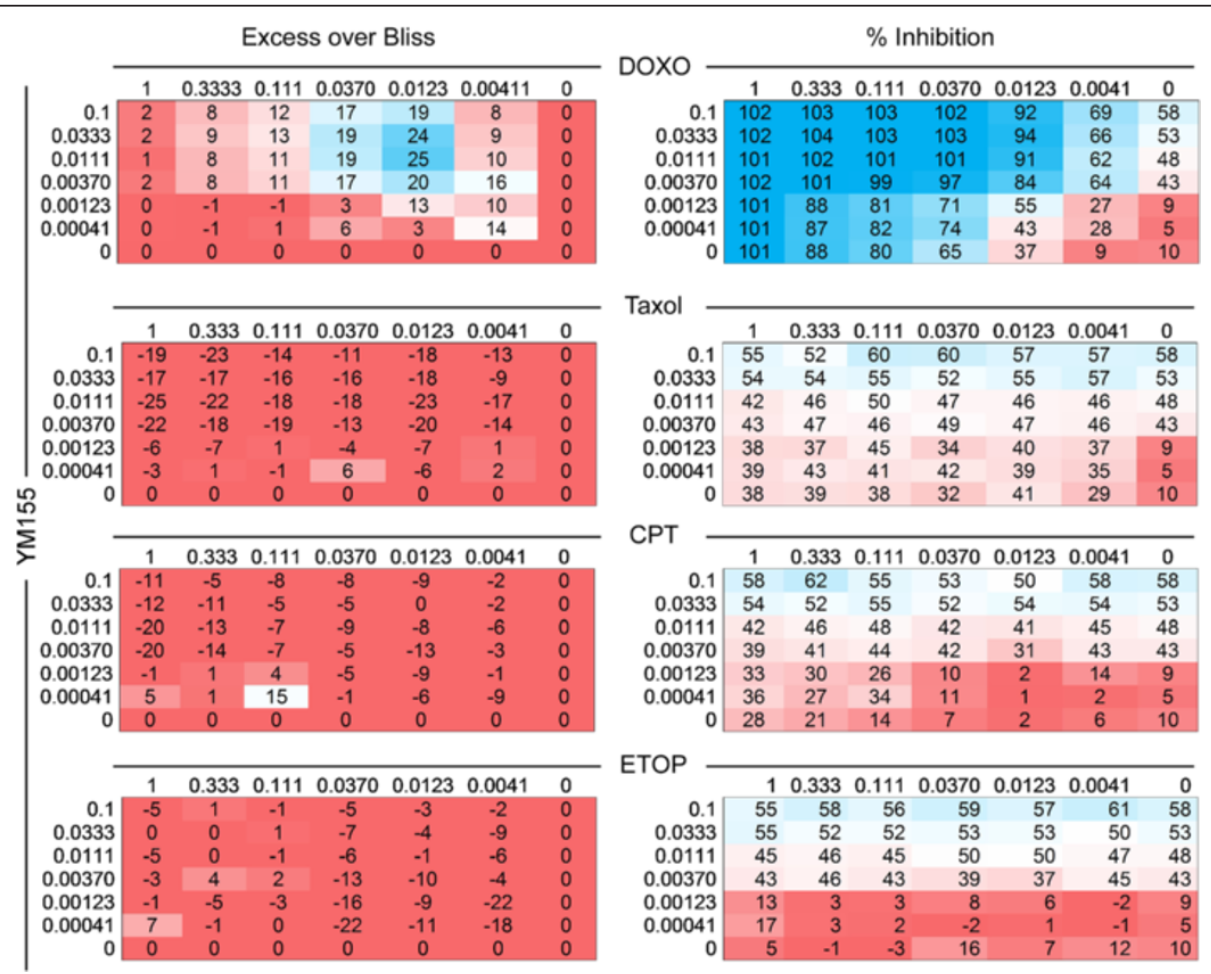

Figure 5 Combination effects of YM155 and cancer chemotherapeutics on breast cancer cell viability. MCF-7 cells were treated with YM155 (dose range 0.0004 to $0.100 \mu \mathrm{mol} / \mathrm{L}$ ), in combination with either doxorubicin (Doxo), taxol, camptothecin (CPT), or etoposide (ETOP, dose range per each agent, 0.004 to $1 \mu \mathrm{mol} / \mathrm{L}$ ) as a $7 \times 7$ matrix of concentrations in a cell viability assay. The excess over BLISS independence (left) and percentage of growth inhibition (right) are shown as a concentration range for each drug combination. 


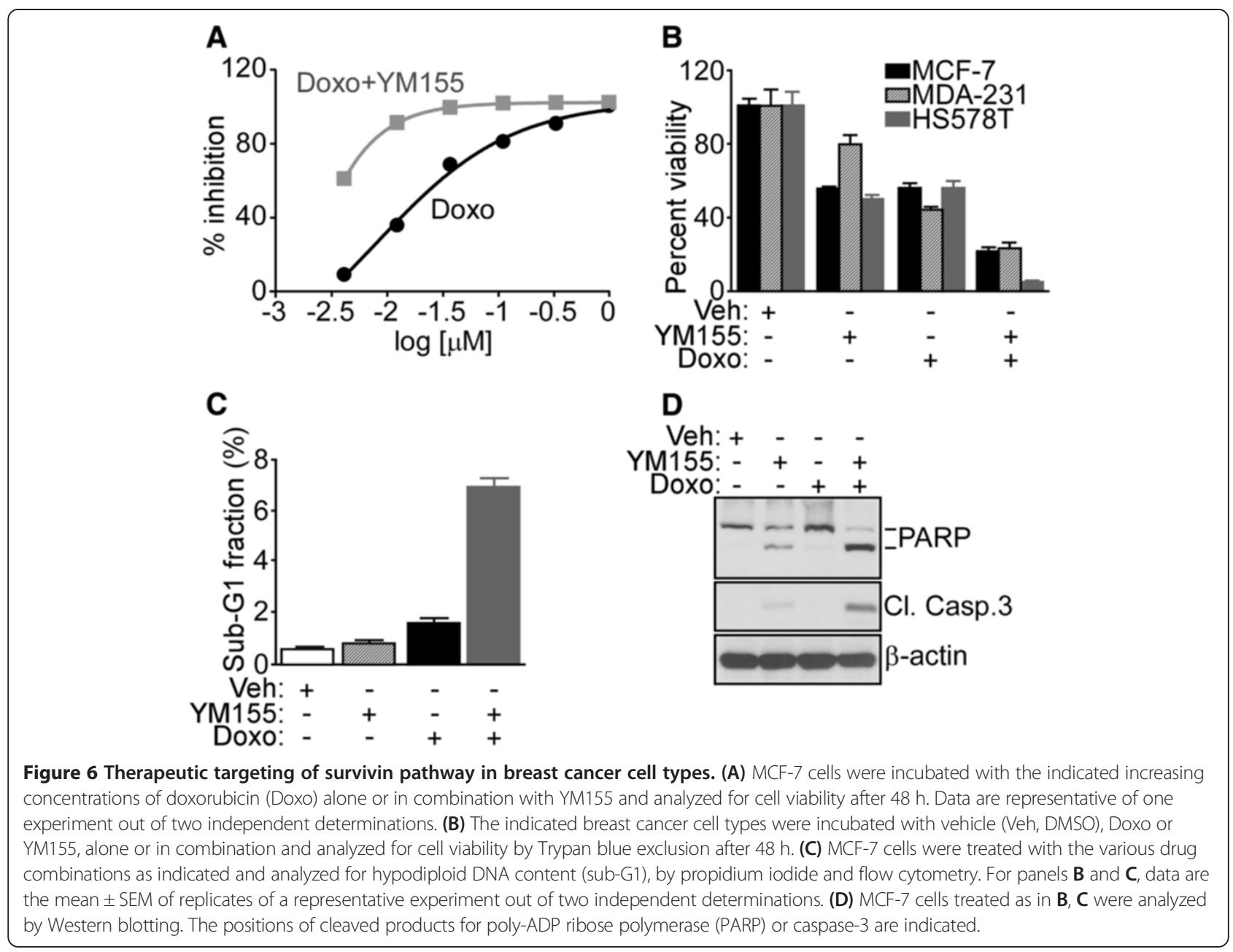

hypodiploid, that is sub-G1 DNA content by flow cytometry (Figure 6C), with increased cleavage of canonical apoptosis markers, including PARP and caspase-3, by Western blotting (Figure 6D).

\section{Discussion}

In this study, we have shown that fresh, treatment-naïve organotypic human breast tumors closely recapitulating the human disease [22] can be stratified into two discrete subgroups that differ sharply in their response to doxorubicin with respect to proliferative status, p53 function and modulation of apoptosis. Doxorubicin-insensitive (that is Non Responder) tumors selectively contained high levels of survivin family proteins, including the alternatively spliced survivin- $\Delta \mathrm{Ex}-3$ isoform, which was directly implicated in treatment resistance. Conversely, high-throughput targeting this pathway with a smallmolecule survivin suppressant currently in the clinic (YM155) selectively synergized with doxorubicin, and restored apoptosis in heterogeneous breast cancer cell types.
Despite the advent of molecular therapies [2], and the improved survival of patients with advanced disease [31], the emergence of treatment-resistant breast cancer, in particular to first-line anthracycline-containing chemotherapy, remains a formidable challenge [10], with limited therapeutic options. The organotypic approach described here [22] identified a functional subset of treatment-naïve breast tumors with nearly complete insensitivity to doxorubicin, characterized by no significant reduction in cell proliferation or appearance of apoptosis in response to treatment. At least in the patient series examined here, the Non Responder phenotype did not appear to segregate with other markers of poor outcome in breast cancer, for instance HER2 overexpression/amplification or p53 mutations. Although analysis of a larger patient cohort may be required to conclusively address this point, the high proliferative status constitutively observed in Non responder breast tumors by Ki-67 staining [32], has been previously associated with drug-resistant disease and poor outcome [33].

The mechanisms of primary drug resistance in breast cancer are still largely elusive [34], but there is evidence 
that aberrant overexpression of antiapoptotic molecules, in particular survivin [29], confers insensitivity to molecular [35,36] or endocrine [37] therapies, resulting in shortened overall survival [38]. Here, the increased expression of survivin and its alternatively spliced survivin$\Delta \mathrm{Ex} 3$ variant provided for the single, most significant deregulation of apoptotic pathways in Non Responder breast tumors, and recombinant expression of survivin$\Delta \mathrm{Ex} 3$ was sufficient, alone, to confer doxorubicin resistance in model breast cancer cell types. It is possible that deregulation of the survivin pathway in Non Responder tumors may reflect the defective p53 responses that were also observed in these patients, as loss of p53-dependent repression of the survivin promoter [39] has been associated with increased survivin gene transcription, including its alternatively spliced variants [40].

Consistent with the data presented here, survivin$\Delta \mathrm{Ex} 3$ has been recognized as a bona fide mediator of cytoprotection, elevating an antiapoptotic threshold in tumors [41]. However, there is also evidence that this molecule may function as a sensor of DNA damage, specifically DSB, and selectively in the transformed cell population [26]. A mechanistic underpinning of this response has been proposed, involving isoform-specific phosphorylation of survivin- $\Delta \mathrm{Ex} 3$ by the checkpoint kinase, Chk2, and time-dependent recruitment of $\gamma \mathrm{H} 2 \mathrm{AX}$, a marker of unrepaired DNA damage [42], to nuclear foci [26]. This scenario may be relevant to the data presented here, as increased expression of survivin- $\Delta \mathrm{Ex} 3$ in Non Responder tumors may promote early recruitment of the DNA repair machinery to DSB, and together with a higher antiapoptotic threshold, limit the anticancer activity of genotoxic stress, including doxorubicin [26]. Indeed survivin- $\Delta \mathrm{Ex} 3$ overexpression may counter the preferential killing of highly proliferating tumor cells by doxorubicin, thus diminishing the efficacy of chemotherapy against this potentially susceptible cellular compartment.

Accordingly, retrospective bioinformatics analyses have linked high expression of survivin- $\Delta \mathrm{Ex} 3$ to unfavorable outcome in various patient series [26], further supporting the more general role of survivin as a poor prognostic marker in breast cancer [43].

Although there is overwhelming evidence that survivin is an important therapeutic target in disparate tumors, including breast cancer [44], the portfolio of survivin antagonists suitable to target this pathway in the clinic has remained disappointingly narrow [15]. Currently, only the small-molecule sepantronium bromide, YM155 [45], proposed to act as a transcriptional suppressant of the survivin locus, has shown good tolerability and preliminary evidence of activity in early-phase trials [44]. On the other hand, survivin is overexpressed in virtually every human tumor [15], making it difficult to identify discrete patient subset(s) likely to benefit from YM155based therapy, and only limited information is available to rationally guide the incorporation of survivin antagonist(s) in effective combination regimens. The present study may help bridge this gap, uncovering a synergistic response between YM155 and doxorubicin that induced apoptosis in heterogeneous breast cancer cell types. Consistent with a role of survivin family proteins in DNA repair mechanisms [26], YM155 triggered a DNA damage response in tumor cells [46], and potentiated the antitumor activity of ionizing radiation in non-small cell lung cancer [47]. Conversely, the combination of YM155 plus taxol, etoposide or camptothecin was not synergistic in our high-throughput analysis, and had minimal anticancer activity in breast cancer cells. This is reminiscent of other data in the clinic, where the combination of YM155 plus carboplatin/paclitaxel produced only limited responses in non-small cell lung cancer patients [48].

\section{Conclusions}

In summary, we used fresh cultures of treatment-naïve organotypic breast tumors that closely mimic the disease in patients [22] to identify survivin family proteins as drivers of primary doxorubicin resistance across breast cancer subgroups. Despite the introduction of YM155 in the clinic over five years ago [30], the suitability of this treatment in breast cancer has not been clearly demonstrated. The results presented here suggest that incorporation of YM155 in anthracycline-containing chemotherapy may result in greater clinical activity across heterogeneous breast cancer subtypes, and potentially overcome constitutive treatment resistance in these patients.

\section{Additional file}

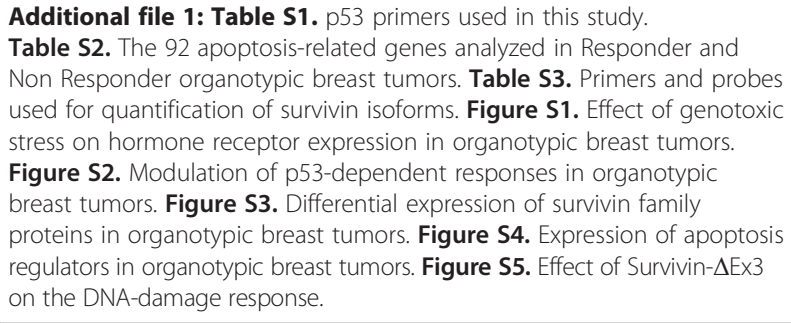

\section{Abbreviations}

Casp3: cleaved caspase-3; CPT: camptothecin; Ctrl: control/vehicle; DAB: 3,3'-diaminobenzidine; DAPI: 4',6-diamidino-2-phenylindole; DLC: ductal and lobular carcinoma; DMEM: Dulbecco's modified Eagle's medium; DMSO: dimethyl sulfoxide; Doxo: doxorubicin; DSB: double-strand DNA breaks; ER: estrogen eceptor; ETOP: etoposide; FBS: fetal bovine serum; FFPE: formalin-fixed and paraffin-embedded; Gl: growth index; H\&E: hematoxylin and eosin; HER2: epidermal growth factor receptor-2; IAP: inhibitor of apoptosis; IDC: invasive ductal carcinoma; ILC: invasive lobular carcinoma; mTOR: mammalian target of rapamycin; MTT: 3-(4,5-dimethylthiazol-2-yl)-2,5 diphenyltetrazolium bromide; PARP: poly-ADP ribose polymerase; PBS: phosphate-buffered saline; PC: papillary carcinoma; 
PFA: paraformaldehyde; PI3K: phosphatidylinositol 3-kinase; PR: progesterone receptor; RQ: relative quantity; SW- $\Delta$ Ex3: survivin- $\Delta$ Ex3; TO: baseline time; TNFa: tumor necrosis factor-alpha; TUNEL: terminal deoxynucleotidyl transferase dUTP nick-end labeling; VEGF: vascular endothelial cell growth factor; Veh: vehicle-DMSO; $ү \mathrm{H} 2 \mathrm{AX}$ : phosphorylated histone H2AX.

\section{Competing interests}

The authors disclose no potential conflicts of interests.

\section{Authors' contributions}

$\mathrm{AF}$ and $\mathrm{W}$ designed and performed experiments and analyzed data. GPM provided patients' clinical information. DT carried out the immunohistochemical experiments. AL performed transfection experiments. DCS and DR carried out combination experiments and synergy studies. DCA and SB conceived of the study, designed and directed the experiments. AF, W, DCA and SB wrote the manuscript. All authors read and approved the final manuscript.

\section{Acknowledgements}

This work was supported by NIH grant CA78810 and CA140043, a gift from the FFANY Corporation (D.C.A.), by Fondazione Cariplo (2010-0846) and Ricerca Corrente 2011 (S.B.).

\section{Author details}

'Division of Pathology, Fondazione IRCCS Ca' Granda Ospedale Maggiore Policlinico, via F. Sforza 35, Milan 20122, Italy. ${ }^{2}$ Breast Unit, Ospedale San Paolo, Milan 20142, Italy. ${ }^{3}$ Department of Health Science, Ospedale San Paolo, University of Milan, via Antonio di Rudinì 8, Milan 20142, Italy. ${ }^{4}$ Molecular Pharmacology Unit, Department of Experimental Oncology and Molecular Medicine, Fondazione IRCCS-Istituto Nazionale Tumori, via Giacomo Venezian 1, Milan 20133, Italy. ${ }^{5}$ Center for Chemical Biology and Translational Medicine, The Wistar Institute, 3601 Spruce Street, Philadelphia, PA 19104, USA. ${ }^{6}$ Molecular and Cellular Oncogenesis Program, The Wistar Institute, 3601 Spruce Street, Philadelphia, PA 19104, USA. 'Department of Pathophysiology and Transplantation, University of Milan, Via Festa del Perdono 7, Milan 20122, Italy.

Received: 9 December 2013 Accepted: 8 May 2014 Published: 30 May 2014

\section{References}

1. Reis-Filho JS, Pusztai L: Gene expression profiling in breast cancer: classification, prognostication, and prediction. Lancet 2011, 378:1812-1823.

2. Chavez-MacGregor M, Gonzalez-Angulo AM: Breast cancer in 2012: New drugs, new knowledge, new targets. Nature Rev Clin Oncol 2013, 10:75-76.

3. Schiff R, Osborne CK: Endocrinology and hormone therapy in breast cancer: new insight into estrogen receptor-alpha function and its implication for endocrine therapy resistance in breast cancer. Breast Cancer Res 2005, 7:205-211.

4. Arteaga CL, Sliwkowski MX, Osborne CK, Perez EA, Puglisi F, Gianni L: Treatment of HER2-positive breast cancer: current status and future perspectives. Nat Rev Clin Oncol 2012, 9:16-32.

5. Chakrabarty A, Sanchez V, Kuba MG, Rinehart C, Arteaga CL: Feedback upregulation of HER3 (ErbB3) expression and activity attenuates antitumor effect of PI3K inhibitors. Proc Natl Acad Sci U S A 2012, 109:2718-2723.

6. Natarajan $\mathrm{K}, \mathrm{Xie} \mathrm{Y}$, Baer MR, Ross DD: Role of breast cancer resistance protein (BCRP/ABCG2) in cancer drug resistance. Biochem Pharmacol 2012, 83:1084-1103.

7. Andre F, Dieci MV, Dubsky P, Sotiriou C, Curigliano G, Denkert C, Loi S: Molecular pathways: involvement of immune pathways in the therapeutic response and outcome in breast cancer. Clin Cancer Res 2013, 19:28-33.

8. Fedele P, Calvani N, Marino A, Orlando L, Schiavone P, Quaranta A, Cinieri S: Targeted agents to reverse resistance to endocrine therapy in metastatic breast cancer: where are we now and where are we going? Crit Rev Oncol Hematol 2012, 84:243-251.

9. Mohd Sharial MS, Crown J, Hennessy BT: Overcoming resistance and restoring sensitivity to HER2-targeted therapies in breast cancer. Ann Oncol 2012, 23:3007-3016.
10. Marquette C, Nabell L: Chemotherapy-resistant metastatic breast cancer. Curr Treat Options Oncol 2012, 13:263-275.

11. Fojo T, Coley HM: The role of efflux pumps in drug-resistant metastatic breast cancer: new insights and treatment strategies. Clin Breast Cancer 2007, 7:749-756.

12. Johnstone RW, Ruefli AA, Lowe SW: Apoptosis: a link between cancer genetics and chemotherapy. Cell 2002, 108:153-164.

13. Chipuk JE, Moldoveanu T, Llambi F, Parsons MJ, Green DR: The BCL-2 family reunion. Mol Cell 2010, 37:299-310.

14. Gyrd-Hansen M, Meier P: IAPs: from caspase inhibitors to modulators of NF-kappa B, inflammation and cancer. Nat Rev Cancer 2010, 10:561-574.

15. Altieri DC: Survivin, cancer networks and pathway-directed drug discovery. Nat Rev Cancer 2008, 8:61-70.

16. Nagata $Y$, Lan KH, Zhou X, Tan M, Esteva FJ, Sahin AA, Klos KS, Li P, Monia BP, Nguyen NT, Hortobagyi GN, Hung MC, Yu D: PTEN activation contributes to tumor inhibition by trastuzumab, and loss of PTEN predicts trastuzumab resistance in patients. Cancer Cell 2004, 6:117-127.

17. Zardavas D, Fumagalli D, Loi S: Phosphatidylinositol 3-kinase/AKT/ mammalian target of rapamycin pathway inhibition: a breakthrough in the management of luminal (ER+/HER2-) breast cancers? Curr Opin Oncol 2012, 24:623-634.

18. Korkaya H, Paulson A, lovino F, Wicha MS: HER2 regulates the mammary stem/progenitor cell population driving tumorigenesis and invasion. Oncogene 2008, 27:6120-6130.

19. Bianco R, Rosa R, Damiano V, Daniele G, Gelardi T, Garofalo S, Tarallo V, De Falco S, Melisi D, Benelli R, Albini A, Ryan A, Ciardiello F, Tortora G: Vascular endothelial growth factor receptor-1 contributes to resistance to anti-epidermal growth factor receptor drugs in human cancer cells. Clin Cancer Res 2008, 14:5069-5080.

20. Barcellos-Hoff MH: Does microenvironment contribute to the etiology of estrogen receptor-negative breast cancer? Clin Cancer Res 2013, 19:541-548

21. Kirby TO, Rivera A, Rein D, Wang M, Ulasov I, Breidenbach M, Kataram M, Contreras JL, Krumdieck C, Yamamoto M, Rots MG, Haisma HJ, Alvarez RD, Mahasreshti PJ, Curiel DT: A novel ex vivo model system for evaluation of conditionally replicative adenoviruses therapeutic efficacy and toxicity. Clin Cancer Res 2004, 10:8697-8703.

22. Vaira V, Fedele G, Pyne S, Fasoli E, Zadra G, Bailey D, Snyder E, Faversani A, Coggi G, Flavin R, Bosari S, Loda M: Preclinical model of organotypic culture for pharmacodynamic profiling of human tumors. Proc Natl Acad Sci U S A 2010, 107:8352-8356.

23. Dowsett M, Nielsen TO, A'Hern R, Bartlett J, Coombes RC, Cuzick J, Ellis M, Henry NL, Hugh JC, Lively T, McShane L, Paik S, Penault-Llorca F, Prudkin L, Regan M, Salter J, Sotiriou C, Smith IE, Viale G, Zujewski JA, Hayes DF, International Ki-67 in Breast Cancer Working Group: Assessment of Ki67 in breast cancer: recommendations from the International Ki67 in Breast Cancer working group. J Natl Cancer Inst 2011, 103:1656-1664.

24. Archer CD, Parton M, Smith IE, Ellis PA, Salter J, Ashley S, Gui G, Sacks N, Ebbs SR, Allum W, Nasiri N, Dowsett M: Early changes in apoptosis and proliferation following primary chemotherapy for breast cancer. Br J Cancer 2003, 89:1035-1041.

25. Vandesompele J, De Preter K, Pattyn F, Poppe B, Van Roy N, De Paepe A Speleman F: Accurate normalization of real-time quantitative RT-PCR data by geometric averaging of multiple internal control genes. Genome Biol 2002, 3. RESEARCH0O34.

26. Lopergolo A, Tavecchio M, Lisanti S, Ghosh JC, Dohi T, Faversani A, Vaira V, Bosari S, Tanigawa N, Delia D, Kossenkov AV, Showe LC, Altieri DC: Chk2 phosphorylation of survivin-DeltaEx3 contributes to a DNA damage-sensing checkpoint in cancer. Cancer Res 2012, 72:3251-3259.

27. Fitzgerald JB, Schoeberl B, Nielsen UB, Sorger PK: Systems biology and combination therapy in the quest for clinical efficacy. Nat Chem Biol 2006, 2:458-466.

28. Simon R, Lam A, Li MC, Ngan M, Menenzes S, Zhao Y: Analysis of gene expression data using BRB-ArrayTools. Cancer Inform 2007, 3:11-17.

29. Altieri DC: Survivin and IAP proteins in cell-death mechanisms. Biochem J 2010, 430:199-205.

30. Tolcher AW, Mita A, Lewis LD, Garrett CR, Till E, Daud Al, Patnaik A, Papadopoulos K, Takimoto C, Bartels P, Keating A, Antonia S: Phase I and pharmacokinetic study of YM155, a small-molecule inhibitor of survivin. J Clin Oncol 2008, 26:5198-5203. 
31. Stern HM: Improving treatment of HER2-positive cancers: opportunities and challenges. Sci Transl Med 2012, 4:127rv2.

32. Yerushalmi R, Woods R, Ravdin PM, Hayes MM, Gelmon KA: Ki67 in breast cancer: prognostic and predictive potential. Lancet Oncol 2010, 11:174-183

33. Nishimura R, Osako T, Okumura Y, Hayashi M, Arima N: Clinical significance of Ki-67 in neoadjuvant chemotherapy for primary breast cancer as a predictor for chemosensitivity and for prognosis. Breast Cancer 2010, 17:269-275

34. Magnani L, Stoeck A, Zhang X, Lanczky A, Mirabella AC, Wang TL, Gyorffy B, Lupien M: Genome-wide reprogramming of the chromatin landscape underlies endocrine therapy resistance in breast cancer. Proc Natl Acad Sci U S A 2013, 110:E1490-E1499.

35. Chakrabarty A, Bhola NE, Sutton C, Ghosh R, Kuba MG, Dave B, Chang JC, Arteaga CL: Trastuzumab-resistant cells rely on a HER2-PI3K-FoxO-survivin axis and are sensitive to PI3K inhibitors. Cancer Res 2013, 73:1190-1200.

36. Chen FL, Xia W, Spector NL: Acquired resistance to small molecule ErbB2 tyrosine kinase inhibitors. Clin Cancer Res 2008, 14:6730-6734.

37. Moriai R, Tsuji N, Moriai M, Kobayashi D, Watanabe N: Survivin plays as a resistant factor against tamoxifen-induced apoptosis in human breast cancer cells. Breast Cancer Res Treat 2009, 117:261-271.

38. Hinnis AR, Luckett JC, Walker RA: Survivin is an independent predictor of short-term survival in poor prognostic breast cancer patients. Br J Cancer 2007, 96:639-645.

39. Hoffman WH, Biade S, Zilfou JT, Chen J, Murphy M: Transcriptional repression of the anti-apoptotic survivin gene by wild type $\mathrm{p} 53$. J Biol Chem 2002, 277:3247-3257.

40. Vegran F, Boidot R, Oudin C, Defrain C, Rebucci M, Lizard-Nacol S: Association of p53 gene alterations with the expression of antiapoptotic survivin splice variants in breast cancer. Oncogene 2007, 26:290-297.

41. Malcles MH, Wang HW, Koumi A, Tsai YH, Yu M, Godfrey A, Boshoff C: Characterisation of the anti-apoptotic function of survivin-DeltaEx3 during TNFalpha-mediated cell death. Br J Cancer 2007, 96:1659-1666.

42. Paull TT, Rogakou EP, Yamazaki V, Kirchgessner CU, Gellert M, Bonner WM: A critical role for histone $\mathrm{H} 2 \mathrm{AX}$ in recruitment of repair factors to nuclear foci after DNA damage. Curr Biol 2000, 10:886-895.

43. Song J, Su H, Zhou YY, Guo LL: Prognostic value of survivin expression in breast cancer patients: a meta-analysis. Tumour Biol 2013, 34:2053-2062.

44. Church DN, Talbot DC: Survivin in solid tumors: rationale for development of inhibitors. Curr Oncol Rep 2012, 14:120-128.

45. Yamanaka K, Nakahara T, Yamauchi T, Kita A, Takeuchi M, Kiyonaga F, Kaneko N, Sasamata M: Antitumor activity of YM155, a selective small-molecule survivin suppressant, alone and in combination with docetaxel in human malignant melanoma models. Clin Cancer Res 2011, 17:5423-5431.

46. Glaros TG, Stockwin LH, Mullendore ME, Smith B, Morrison BL, Newton DL: The "survivin suppressants" NSC 80467 and YM155 induce a DNA damage response. Cancer Chemother Pharmacol 2012, 70:207-212.

47. Iwasa T, Okamoto I, Suzuki M, Nakahara T, Yamanaka K, Hatashita E, Yamada Y, Fukuoka M, Ono K, Nakagawa K: Radiosensitizing effect of YM155, a novel small-molecule survivin suppressant, in non-small cell lung cancer cell lines. Clin Cancer Res 2008, 14:6496-6504.

48. Kelly RJ, Thomas A, Rajan A, Chun G, Lopez-Chavez A, Szabo E, Spencer S, Carter CA, Guha U, Khozin S, Poondru S, Van Sant C, Keating A, Steinberg SM, Figg W, Giaccone G: A phase I/II study of sepantronium bromide (YM155, survivin suppressor) with paclitaxel and carboplatin in patients with advanced non-small-cell lung cancer. Ann Oncol 2013, 24:2601-2606.

doi:10.1186/bcr3666

Cite this article as: Faversani et al:: Survivin family proteins as novel molecular determinants of doxorubicin resistance in organotypic human breast tumors. Breast Cancer Research 2014 16:R55.

\section{Submit your next manuscript to BioMed Central and take full advantage of:}

- Convenient online submission

- Thorough peer review

- No space constraints or color figure charges

- Immediate publication on acceptance

- Inclusion in PubMed, CAS, Scopus and Google Scholar

- Research which is freely available for redistribution

Submit your manuscript at www.biomedcentral.com/submit
Ciomed Central 